\title{
FURTHER EXPLORATIONS ON REGIONALISM AND POLITICAL OPINION IN ARKANSAS
}

\author{
Diane D. Blair \\ William D. Mangold \\ Robert L. Savage \\ (University of Arkansas at Fayetteville)
}

While some persist in arguing that Arkansas politics is inexplicable in any systematic way, others continue to attempt to find some reliable, predictable patterns in regional political preferences and voting behavior. In 1984, Savage and Blair reviewed the intrastate distinctions that had been traditionally offered in explanation of Arkansas politics, and then tested some of those generalizations against contemporary public opinion data.

By including an array of political questions in the quarterly survey conducted by the Arkansas Household Research Panel (AHRP) of the University of Arkansas, and examining the responses in terms of the state's eight economic development districts (see Figure 1), Savage and Blair (1984) came to the following broad conclusions. First, while there are strong and obvious commonalties in Arkansans' political attitudes, there are also some measurable, even marked, regional variations in their political values and opinions on contemporary policy issues. Second, while the findings provided some confirmation of the traditionally ascribed Ozark/Delta diagonal division of Arkansas between the northern and western hills as opposed to the eastern and southern flatlands, the findings also revealed that-with regard to at least some current state policy issues - some of the widest ranges of disagreement occurred within areas that have often been conceived of as consensual regions. In short, the findings seemed partially to confirm and yet also to challenge conventional wisdom about regional variations in Arkansas politics.

While Savage and Blair felt sufficiently confident in their findings to offer them as "a tentative first step at sketching the attitudinal geography of Arkansas politics" (1984: 62), certain caveats and concerns were acknowledged about the size of the sample (523 respondents with necessarily much smaller sub-samples for each of the eight regions) and the 
Figure 1. ECONOMIC DEVELOPMENT DISTRICTS OF ARKANSAS

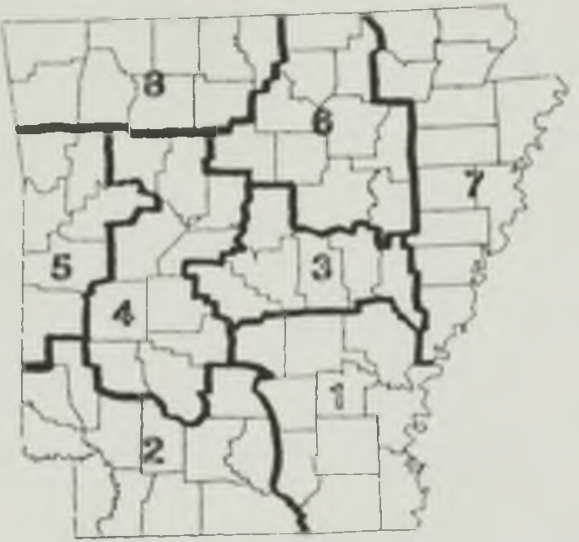

$\begin{array}{cl}\text { ECONOMIC DISTRICTS } \\ 1 & \text { SOUTHEAST } \\ 2 & \text { SOUTHWEST } \\ 3 & \text { CENTRAL } \\ 4 & \text { WEST CENTRAL } \\ 5 & \text { WEST } \\ 6 & \text { WHITE RIVER } \\ 7 & \text { EAST } \\ 8 & \text { NORTHWEST }\end{array}$

unrepresentative character of the sample demographically: AHRP respondents tend to be more often white, somewhat older, wealthier, and bettereducated than the Arkansas population generally.

In the summer of 1986, the Center for Social Research (CSR) at the University of Arkansas conducted 1061 telephone interviews with Arkansas residents age 18 and over using random-digit dialing. This procedure produced a much more representative sample of Arkansans (see Appendix). Because these interviews, like the AHRP responses, were coded for economic development districts, an inviting opportunity presents itself for comparing what the two sets of data might together reveal regarding regional variations in political opinions in Arkansas. ${ }^{1}$

At the outset, the focus was on some fairly clearcut descriptive and analytic tasks. Would the later, larger, and more representative data-set confirm, deny, or qualify the existence of regional variations? If regional variations again appeared, would they be similar to or different from the variations previously found? Are some regions more consistently deviant from state norms than others? Increasingly, however-reflecting one positive byproduct of interdisciplinary dialogue-the present authors found themselves equally intrigued with another set of questions. If regional variations in public opinion do in fact exist, how can they best be explained? What combination of geography, economics, demographics, political culture, or other factors best accounts for intrastate opinion variations? In short, what does one really mean when one says "region"? First, however, the more descriptive questions are addressed and then some efforts at exploring the puzzle of regional variations are offered.

\section{Persistence and Consistency in Regional Opinion Differences}

As several earlier descriptions of Arkansas' political values suggest (Key, 1949: 184-185; Savage and Gallagher, 1977: 97), as Savage and Blair confirmed (1984: 70), and as the CSR data again substantiate, there 
are some very strong commonalties in the political attitudes of Arkansans. Certain issues, in fact, reflect consensual response pattems. A strong majority of Arkansans, for example believe that the amount of money being spent on public education in the state should be increased (76\%). There is widespread support (74\%) for the death penalty for persons convicted of murder and an even more widespread belief ( $82 \%)$ that courts are not dealing harshly enough with criminals. There is sizeable support (76\%) for a pregnant woman being allowed to obtain an abortion legally if there is a strong chance of serious defect in the baby. Arkansans overwhelmingly believe ( $88 \%$ ) that white and black students should attend the same schools, and presumably to pray together, given Arkansans' $80 \%$ disapproval of the U.S. Supreme Court's rulings restricting school prayer.

One must be careful, assuredly, in assuming the operative value of such consensus. Approval of more school revenues and school integration may be much stronger in the abstract than they are in the particular instance of one's own taxes being hiked or one's own child being bussed across town. Nevertheless, there are some opinions and values which, given the relative lack of controversy, may be termed "motherhood" issues (except, paradoxically, a question regarding gender equality was one of the most starkly divisive items in the 1986 survey). Still, the point is that some "issues" are almost non-issues in Arkansas presently.

Bound up in this high level of homogeneity, however, are persistent regional variations. All 38 questions used in the present analysis from the 1986 survey produced at least some incidence of regional variation (marked by a region deviating from the state norm by five percent or more). No region deviated on less than fourteen questions and one region deviated on as many as 26 of the items. Even on clearly consensual items, there were notable regional variations in the spread of consensus, and even stronger variances were assuredly found with regard to non-consensual items.

The 1982 survey reported in Savage and Blair (1984), if anything, showed even more marked regional differences in opinion distributions. For 55 of the 57 opinion questions reported there, one or more regions deviated by ten percent or more from the state norm in response distributions. For the other two questions there were deviations of five percent or more. Of the 38 questions from the 1986 survey, regional deviations of ten percent or more appear for thirty questions and of five percent or more for the remaining eight items. Regional variations in opinion distributions, then, are persistent, even pervasive, in Arkansas.

The continuing existence of so much regional variation measured so 
rawly, however, does not establish that characteristic ways of thinking about political matters are associated with particular geographical areas. Unfortunately, systematic analysis of this question can be pursued only to a limited extent. The surveys of 1982 and 1986 were developed by researchers from different disciplines for purposes only somewhat similar and drawing upon different survey "traditions" (the 1982 study derived largely from the Michigan SRC surveys while the 1986 study harks to the General Social Survey). Still, some rough commonalities in the focus of some of the questions from both surveys permit some conclusions to be drawn.

The 1982 survey featured a seven-point scale item regarding the severity of criminal courts in their sentencing policies. The 1986 survey asked more simply if the courts deal too harshly or not harshly enough with criminals. In the earlier survey, Northwest Arkansans were the least likely to opt for "stricter punishments and longer sentences," albeit a majority of them (52.8\%) took this position to some degree. Southeast Arkansans supported this position at a significantly higher rate $(63.6 \%)$ but still below the state sample's overall $68.7 \%$ endorsement of the position. On the other extreme, $81.8 \%$ of West Arkansans and $77.5 \%$ of Southwest Arkansans adopted this more conservative position. In the 1986 survey, these regional tendencies are only partially evident. For the state as a whole, $82.3 \%$ of those offering an opinion believe that the courts are not harsh enough. Regionally, Southeasterners (71.4\%) and Easterners $(75.2 \%)$ were least likely to take the harshest position, and Southwesterners (88.0\%), White River residents (87.5\%), and West Central Arkansans $(87.4 \%)$ most likely to adopt this view.

Similar results follow from questions relating to gender roles. The 1982 survey featured another seven-point scale question posing the opposites "women and men should have an equal role" and "women's place is in the home." Across the state, only a small majority (54.3\%) chose the more egalitarian view, yet Central Arkansans were much more likely to opt for equality (65.1\%) with West Central Arkansans a distant second $(56.3 \%)$, only marginally above the state norm. Southwest Arkansans (39.2\%) and White River residents (40.0\%) werc the least supportive of female equality. In $1986,52.5 \%$ of those responding from across the state rejected the notion that "the man should be the breadwinner." Once again, Central Arkansans were more inclined to take the feminist view $(60.8 \%)$ but they were closely followed by respondents from the Northwest (59.7\%). Southeasterners were the most traditional in their responses this time with only $40.6 \%$ rejecting the proposition, followed closely by 
respondents from the White River area (42.1\%) and the Southwest $(43.4 \%)$. The findings suggest, despite the differences in the sampling procedures and the differences in question wording, that there are substantial regional variations with regard to this fundamental social value.

There are other complementary questions from the two surveys that could be examined similarly, but the greater differences in question wording make any conclusions all the more problematic. An altemative procedure is to follow one method adopted in the earlier study by Savage and Blair (1984), that of regional profiles based on the patterning of deviance from state norms. Accordingly, thumbnail sketches of the eight regions based on the 1986 survey data are offered along with pertinent observations regarding the fit of these sketches with those flowing from the 1982 survey.

Since the sketches are based upon deviance from the state distributions of opinion, a brief portrait of the prevailing pattern of opinion across Arkansas in 1986 is necessary. This survey contained questions on contemporary social issues, confidence in institutions, satisfaction with some institutions and life circumstances, international relations, optimism and pessimism (especially with regard to economic concerns), and issues of public finance. With respect to social issues, Arkansans hardly reflect the proverbial wisdom that lumps them with other Southerners as archconservatives or traditionalists. The pattern is more mixed with Arkansans especially likely to take a more conservative position by supporting harsher criminal punishments and prayer in the schools. They are also less likely to support easing divorce requirements or allowing abortion on demand. On the other hand, they generally take more liberal positions by supporting gun permits, racial integration of schools, abortion where a likely defective baby is involved, and (barely) gender equality. Arkansans reflect patterns of institutional confidence similar to those found in the nation and other states with a rise in that confidence similar to those found in the nation and other states with a rise in that confidence compared to earlier surveys in Arkansas during the 1980s (see Savage and Darden, 1985). Arkansans are generally satisfied with their lot except for the now proverbial lack of job opportunities in the state. Moreover, despite the problem with job opportunities, people of the state largely do not exhibit a pessimistic outlook. And somewhat contrary to prevailing images, Arkansans tend toward supporting an activist role for the nation in the international arena although they do not support a free trade position. Finally, Arkansans are supportive of providing more funding for public schools (75.6\%) with most of this supporting group (80.8\%) willing to pay higher 
taxes for the purpose. In the regional sketches that follow, then, one should recognize that this more general pattern tends to prevail everywhere in the state. The sketches focus upon the more and less, or deviating tendencies, of the regions.

At the same time, some regions are more deviant and others less in terms of either or both the variety of questions and the extent of deviance. For example, the Southwest edges out the East in the number of questions for which the regions vary five percent or more from the state distribution, 26 to 25. On the other hand, the Southeast deviates ten percent or more on ten questions and White River and the West do so on eight questions each where for the Southwest and the East these values are four and six respectively. Generally, however, White River, the East, the Southeast, the Southwest, and the West are more deviant; the Northwest, Central, and West Central regions are less deviant (but note that the Central region provided almost $30 \%$ of the state sample given that it is the most populous region, hence it may appear less deviant relative to Arkansans outside that region that it actually is).

The Southeast stands out most clearly for the greater degree of institutional confidence it exhibits. Indeed, the percentage of respondents indicating "a great deal" of confidence exceeds the percentage for any other region for seven of the ten institutions covered in the survey: Arkansas financial institutions, churches, public schools, newspapers, television stations, the Congressional delegation, and the governor, while falling below the state norm only for Arkansas businesses. The Southeasterners, like Arkansans generally, exhibit a mixed response on social issues but move in opposite directions on some issues: less harsh on punishment of criminals, less supportive of gender equality and school integration, but more supportive of prayers in schools. Compared to 1982, this profile seems to describe an altogether different population. Then, Southeasterners were noticeably less deviant generally, and the one trait that most clearly marked the region was opposition to the national government suggesting that Dixie still lived on in their hearts. The 1986 survey also reflects this to some extent sinre. Southeasterners selected the national level as the level of government in which they has the most confidence to a lesser extent $(25.4 \%)$ than any other region. That so few blacks were included in the AHRP panel may explain the differences but the emergent 1986 profile does not clearly argue for that explanation.

In 1982, White River respondents were most notable for their social conservatism and their desire for less influence to be wielded by organized interests upon governmental action. The 1986 survey provides no data 
with which to assess the second trait, but conservatism on social issues remains clearly evident. White River residents are more often conservative than state residents generally on punishment of criminals, capital punishment, divorce, and especially gender equality. They are also somewhat more likely to express a great deal of confidence with regard to certain institutions but it is precisely those institutions that tend to receive more universal support everywhere: churches, higher education, financial institutions, and public schools. While the more limited array of questions available in the later survey do not provide support for the fuller sketch of the region provided by Savage and Blair (1984), neither do the later findings contradict it.

East Arkansans in 1982 could essentially be described as political conservatives. In 1986, this was probably no less true, at least with regard to social issues such as punishment of criminals, gender equality, school integration, and abortion. Respondents in this region also were second only to Southeasterners in their confidence in the state's institutions generally. At the same time, Easterners exhibit less satisfaction than the state's population as a whole, notably with respect to courts, police, hospitals, and, more than for any other region, recreation and entertainment. East Arkansans also somewhat more often more correctly perceive the state's lower tax burden and are more inclined toward an active involvement by Americans in the larger world with less in the way of trade barriers. Ultimately, though, they are more pessimistic about their economic future. East Arkansans, then, just have less fun.

West Arkansans in 1986 seemingly enjoy life a great deal more. They tend to be more optimistic about their economic future, and only with respect to local government are their satisfaction levels notably lower than the rest of the state. Of special note is that Westerners are the most satisfied where job opportunities are concerned. Not surprisingly, then, West Arkansans exhibit the widest support for increasing school revenues. Ironically, however, they are relatively parochial when it comes to international involvement, including a stronger propensity to restrict imports. The 1982 profile emphasized conservatism and economic boosterism as primary traits of the region. The 1986 profile only indirectly supports this, particularly with regard to conservatism. Yet, in 1982, that conservatism was reflected more often on economic issues and generally much less on social issues. The economic policy issues included in the 1982 survey do not appear in the later survey. Accordingly, the later profile in no way necessarily disavows the earlier one.

Southwesterners, as noted above, deviate on more questions than any 
other region. Generally, they are the most conservative, the most parochial, the most pessimistic, and the least satisfied people in the state at least on the basis of regional distribution. Compared to 1982, the only one of the traits that can be clearly assessed is the political conservatism. That conservative tendency just as clearly continues to characterize the region. There is some indirect support for some of the other traits in the generally lower levels of institutional confidence then, a tendency that continues in 1986 also.

Although Northwest Arkansas deviated five percent or more from the state norm on half of the questions in 1986, in only two instances did the deviance exceed ten percent. In part this reflects the fact that the region has the second largest group in the sample and an opinion profile somewhat similar to the largest sub-sample, the Central district respondents. Yet, the Northwest is rather distinctive from the other regions generally and, consequently, from the state's profile as well. This difference is best reflected with regard to social issues where the region deviates on four measures-school prayers, gender equality, and the two abortion questions - all in the more liberal direction. The Northwest shares with East Arkansas the distinction of being most internationalist in American foreign affairs. Also like the Easterners, people of the Northwest tend more toward the correct perception of the state's tax burden. In general, the Northwest Arkansas opinion profile suggests a somewhat more cosmopolitan outlook albeit not radically outside the Arkansas mainstream. In 1982, the region's opinion profile reflected a greater "apartness" from the state more than anything else. That does not seem to be the case in 1986 given that the region mirrors the state distribution on the question most directly measuring this, the relative confidence in the three levels of American government.

Central Arkansas generally seems a weaker version of the Northwest. Since the region is so important in determining the state norm and is the most urbanized area of the state, this should not be so surprising. The two opinion items for which Central Arkansas is the most deviant, on the other hand, are more peculiar to the region. The region exhibited noticeably less confidence in financial institutions and the public schools, no doubt reflecting the perceived realities of Little Rock area residents in 1986, when troubles in both sets of institutions locally seemed almost daily to be front-page news. As compared to 1982, the Central region seems less clearly the most liberal area on policy issues, but this may simply be an artifactural result given the fewer policy issues that can be characterized in liberal/conservative terms appearing in the later survey. 
Finally, the least distinct region in the 1986 survey is the West Central. In the 1982 survey, the region was assuredly not the most deviant region, and yet it was in many respects the most idiosyncratic of the eight regions (see Savage and Blair, 1984: 68-69). The "washout' of the West Central region could reflect that the region is the true regional bellwether for the rest of the state. If so, then the 1982 survey results must be considered altogether aberrant, a possibility given the sampling problems already mentioned. A more tenable explanation and one that suggests a continuing problem for studies of regionalism utilizing opinion data is that the 1982 survey simply contained some questions that touched, shall one say, the "idiosyncratic nerve" of the West Central region, and the 1986 survey does not.

\section{Problems in Regional Opinion Analysis}

Indeed, developing appropriate index questions for characterizing and/or demarcating regions is a central problem for regional analysis. An even greater problem for such analyses, however, is the multidimensionality of opinion distributions within specified areal populations. Even if an appropriate set of marker questions is developed for continuing study of regional opinion distributions in Arkansas, there will continue to be difficulties in determining the bases of regional cleavages. At any given point in time, one or another of three sources of such cleavages may be acting so as to disrupt past understandings. These three sources-cultural legacy, immediate environmental stimuli, and demographic composition - are unlikely to sit still from survey to survey as scholars try to forge moving pictures from what are only occasional snapshots. Presumably the most stable of these influences, cultural legacy, must first be isolated, and in that regard present knowledge is still at a very exploratory stage.

Another source of regional differences lies in contemporary environmental circumstances and stimuli. It is not difficult to imagine why Central Arkansans more often expressed dissatisfaction with public schools in the summer of 1986, for example, or why respondents in the Southwest, with so many highly publicized instances of Texas financial institutions failing, would more often express "hardly any" confidence in Arkansas financial institutions. It is, moreover, reasonable that residents of Central and Western Arkansas should be much more satisfied with their more plentiful hospital facilities than are residents of Eastern and Southeastern Arkansas, and reasonable also that Central Arkansans should be 
more satisfied with their recreational and entertainment opportunities than Arkansans elsewhere. And job opportunities in West and Northwest Arkansas were in fact more abundant in 1986 then they were in West Central, Southeast, and East Arkansas. Regional variations, then, can at least in part be ascribed to more or less accurate perceptions of varying intrastate realities in a constantly changing environment.

Finally, any region has its own more or less distinctive demographic composition that will impact upon opinion distributions. One must ask to what extent a region deviates from prevailing opinion in the larger community simply because its people are richer or poorer, better or less-well educated, etc.

While it is clear that there are substantial differences in the opinions and attitudes held among Arkansans in the eight planning regions, these regions also vary considerably in terms of other characteristics which affect attitudes and opinions. It is well known, for example, that the demographic composition of a region has a major effect on attitudes. To the extent that the eight planning regions are composed of individuals of differing age, education or race, then it should be expected, other factors being equal, that an aggregate measure of an attitude would reflect these differences. From this perspective, the observed difference in attitudes has two components: the first is the extent of which there is a "true" difference among regions, i.e., that a unique cultural element exists which produces a different set of attitudes. The second is the extent to which individuals in each region differ in terms of their personal characteristics. In general, observed attitudinal differences among regions are determined by both sets of factors. However, it is possible for an observed difference to be the result of individual characteristics. For example, two regions could display different opinions about Social Security because one region contained a larger proportion of old people, but not because people of the same age in each region held differing views. Given the effects which individual characteristics have on attitudes, it is important to control for these characteristics when comparing different populations. Only by examining attitudes after the effects of individual characteristics have been controlled is it possible to make meaningful attitudinal contrasts.

To what extent are the observed differences in Arkansas planning regions the result of a "true" attitudinal difference? How much of the observed difference is due to individual characteristics? To explore these issues the response to two questions which reflect a conservative agenda are examined. These examples will be used to illustrate an approach--a detailed analysis for all variables used in this essay will not be presented. 
The first deals with prayer in public school; the second the role of women.

Table 1 contains the response to the question about the Supreme Court's ban on prayer in public schools for each of Arkansas' planning regions. As can be seen, there is considerable variation with 8.8 percent of respondents in the Southwest indicating approval as opposed to nearly 30 percent in the Northwest. Table 2 contains the distribution to a question about the role of women. Again, there are sharply drawn regional differences with about 40 percent of respondents in the Northwest and Central regions stating a preference for the traditional role of women while nearly 60 percent of the respondents in the White River, Southeast and Southwest responded similarly.

Table 1. Attitudes About Prayer in Public Schools by Planning Region

\begin{tabular}{|c|c|c|c|c|c|c|c|c|c|}
\hline Approve of Court's & \multirow[b]{2}{*}{ NW } & \multicolumn{4}{|c|}{ PLA N N I N G } & \multicolumn{2}{|c|}{ REG I $0 \mathrm{~N}$} & \multirow[b]{2}{*}{ W } & \multirow[b]{2}{*}{ Tota } \\
\hline Ban on Prayer (\%) & & WR & EA & SE & C & WC & SW & & \\
\hline Yes & 29.9 & 24.6 & 17.3 & 12.9 & 25.0 & 18.4 & 8.8 & 14.1 & 20.8 \\
\hline No & 70.1 & 75.4 & 82.7 & 87.1 & 75.0 & 81.6 & 91.2 & 85.9 & 79.2 \\
\hline $\begin{array}{l}\text { Total } \\
\text { Number }\end{array}$ & $\begin{array}{l}100 \% \\
(149)\end{array}$ & $\begin{array}{c}100 \% \\
(56)\end{array}$ & $\begin{array}{l}100 \% \\
(139)\end{array}$ & $\begin{array}{l}100 \% \\
(131)\end{array}$ & $\begin{array}{l}100 \% \\
(305)\end{array}$ & $\begin{array}{c}100 \% \\
(98)\end{array}$ & $\begin{array}{l}100 \% \\
(82)\end{array}$ & $\begin{array}{l}100 \% \\
(81)\end{array}$ & $\begin{array}{l}100 \% \\
(981)\end{array}$ \\
\hline
\end{tabular}

$X^{2}=20.6(7): p<.005$

Question: The Supreme Court has ruled that a state or local government cannot require the reading of the Lord's Prayer or Bible verses in public schools. Do you approve or disapprove of this ruling?

Table 2. Attitudes About Role of Women by Planning Region

\section{PLA N N 1 NG RE G I O N}

Women should stay

at home $(\%) \ldots$

Yes

\begin{tabular}{ccccccccc} 
NW & WR & EA & SE & C & WC & SW & W & Total \\
\hline 40.3 & 57.9 & 54.7 & 59.4 & 39.2 & 48.5 & 56.6 & 51.6 & 47.5 \\
59.7 & 42.1 & 45.3 & 40.6 & 60.8 & 51.5 & 43.4 & 48.4 & 52.5
\end{tabular}

No

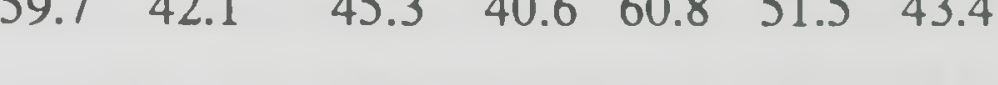

$\begin{array}{lllllllllll}\text { Total } & 100 \% & 100 \% & 100 \% & 100 \% & 100 \% & 100 \% & 100 \% & 100 \% & 100 \%\end{array}$

Number (149) (56) (139) (131) (305) (98) (82) (81) (981)

$\mathrm{X}^{2} 24.4(7): \mathrm{p}<.001$

Question: Do you think that it would be better for everyone if the man was the breadwinner and the woman took care of the home? 
Tables 3 and 4 reveal that the respondents' educational attainment has a dramatic effect on these attitudes. As can be seen, the proportion of college-educated Arkansans who approve of the ban on prayer is nearly three times higher than is true of individuals who failed to graduate from high school. When the attitude about the role of women is considered, respondents who failed to graduate from high school are two times more likely to feel that a woman's place is in the home.

Table 3. Attitudes About Prayer in Schools by Educational Attainment

\begin{tabular}{|c|c|c|c|c|c|}
\hline \multirow{2}{*}{$\begin{array}{l}\text { Approve of Court's } \\
\text { Ban on Prayer (\%) }\end{array}$} & \multicolumn{2}{|c|}{ EDUCATION } & \multicolumn{3}{|c|}{ OF RESPONDENT } \\
\hline & $0-11$ & 12 & $13-15$ & $16 \&$ up & Total \\
\hline Yes & 13.4 & 16.9 & 17.9 & 37.9 & 20.5 \\
\hline No & 86.6 & 83.1 & 82.1 & 62.1 & 79.5 \\
\hline Total & $\begin{array}{l}100 \% \\
(213)\end{array}$ & $\begin{array}{l}100 \% \\
(405)\end{array}$ & $\begin{array}{l}100 \% \\
(231)\end{array}$ & $\begin{array}{l}100 \% \\
(212)\end{array}$ & $\begin{array}{r}100 \% \\
(1061)\end{array}$ \\
\hline
\end{tabular}

$\mathrm{X}^{2} 48.7(3): \mathrm{p}<.00001$

Table 4. Attitudes About Role of Women by Educational Attainment

\section{EDUCATION OF RESPONDENT}

Women should stay

at home $(\%)$...

Yes

No

\begin{tabular}{lllll}
$\mathbf{0 - 1 1}$ & $\mathbf{1 2}$ & $\mathbf{1 3 - 1 5}$ & $\mathbf{1 6} \boldsymbol{\&}$ up & Total \\
\hline 70.7 & 47.2 & 38.9 & 34.0 & 47.4 \\
29.3 & 52.8 & 61.1 & 66.0 & 52.6
\end{tabular}

Total

$100 \% \quad 100 \% \quad 100 \% \quad 100 \%$

(213) (405) (231) (212)

$x^{2}=67.0(3): p<.00001$

Table 5 shows the educational attainment for each of the planning regions and documents the extent of educational differences among regions. For example, the proportion of college graduates is three times higher in the Central region and over two times higher in the Northwest region than is true of the Southwest region. 
Table 5. Educational Attainment by Planning Region

\begin{tabular}{llllllllll}
\hline & \multicolumn{8}{c}{ P L A N N I N G } & R E G I 0 N \\
Education & NW & WR & EA & SE & C & WC & SW & W & Total \\
\cline { 2 - 10 } $0-11$ & 13.5 & 12.3 & 32.6 & 31.0 & 12.5 & 26.7 & 24.7 & 18.5 & 19.7 \\
12 & 40.4 & 52.6 & 35.5 & 40.8 & 31.9 & 45.7 & 41.2 & 39.1 & 38.3 \\
$15-15$ & 23.7 & 19.3 & 14.2 & 12.7 & 26.2 & 16.2 & 23.5 & 28.3 & 21.8 \\
16 \& up & 22.4 & 15.8 & 17.7 & 15.5 & 29.4 & 11.4 & 10.6 & 14.1 & 20.2 \\
& $100.0 \%$ & $100.0 \%$ & $100.0 \%$ & $100.0 \%$ & $100.0 \%$ & $100.0 \%$ & $100.0 \%$ & $100.0 \%$ & $100.0 \%$ \\
& $(149)$ & $(56)$ & $(139)$ & $(131)$ & $(305)$ & $(98)$ & $(82)$ & $(81)$ & $(981)$ \\
\hline
\end{tabular}

$\mathrm{X}^{2} 79.8(21): \mathrm{p}<.00001$

When the distributions of attitudes by educational attainment are examined relative to the extent of regional differences in educational attainment, it is obvious that a portion of the regional attitudinal differences which were observed earlier are the result of different levels of education. What would the regional differences be if each region had the same level of education? That is, how much of the observed regional difference in attitudes about prayer in school or the role of women is due to a unique regional difference and how much is an artifact of educational differences?

Although an arsenal of multivariate procedures exists which can be used to explore that question, they are inappropriate for nominal scale attitudinal data. There is, however, an approach which has been widely used in demography which is appropriate for this type of data. The technique is called "expected case analysis" or direct standardization. Direct standardization utilizes the proportional distribution of a characteristic (such as education attainment) of a standard or reference population (region) to calculate a rate (attitude) which would be expected if all populations were the same as the standard population. By directly standardizing a series of populations against one reference it is possible to decompose the observed differences into two components: the part due to a unique rate difference and the part due to compositional differences.

Mathematically the technique can be represented as:

For any population, the rate for an observed (o) population can be defined as: $\Sigma \mathrm{R}_{\mathrm{io}} * \mathrm{P}_{\mathrm{io}} / \Sigma \mathrm{P}_{\mathrm{io}}$ where $\mathrm{R}_{\mathrm{io}}$ is the proportion in the $\mathrm{i}$ th educational category of the observed population who approve of a statement and $P$ is the number of people in the $\mathrm{i}$ th category of the observed population. Similarly, the rate for a standard (s) population can be defined as: $\sum \mathrm{R}_{\mathrm{is}} * \mathrm{P}_{\mathrm{w}} \Omega \mathrm{P}_{\text {is }}$ where $\mathrm{R}_{\mathrm{is}}$ is the proportion in the $\mathrm{i}$ th educational category of the standard population who approve 
of a statement and $\mathrm{P}_{\text {is }}$ is the number of people in the $\mathrm{i}$ th category of the standard population. Thus, the observed difference between the standard and the observed population is:

$\left(\sum \mathrm{Ri}_{\mathrm{a}} * \mathrm{Pi}_{8} / \sum \mathrm{Pi}_{8}\right)-\left(\sum \mathrm{Ri}_{\mathrm{o}} * \mathrm{Pi}_{\mathrm{o}} / \sum \mathrm{Pi}_{0}\right)$

and the expected difference is:

$\left(\sum \mathrm{Ri}_{3} * \mathrm{Pi}_{8} / \sum \mathrm{Pi}_{\mathrm{g}}\right)-\left(\sum \mathrm{Ri}_{0} * \mathrm{Pi}_{s} / \Sigma \mathrm{Pi}_{8}\right)$

As can be seen from the preceding, the expected rate is simply the sum of the category-specific rates in the observed population multiplied by the number of each category in the standard population divided by the total population of the standard population. This general approach can be extended to include additional characteristics.

Table 6 presents the observed and expected proportion (rate) for the attitude about prayer in public schools for each of the planning regions. For these calculations the population of the Northwest region is used as the standard. The first row of the table contains the proportion of respondents who approve of the Supreme Court's ban on prayer in public schools. These are identical to the corresponding values displayed in Table 1.

The next row of the table contains the difference between each of the regions and the Northwest region. As can be seen, the differences are relatively slight for the White River and Central regions (4.0 and 4.9 percent) but are quite large for the remaining districts. The next row contains the expected proportions in each region who would approve of the Court's ban on prayer, if they had the same educational composition as the Northwest As can be seen, the proportions approving of the Court's ruling would increase in every region except the Southwest and Central. These results indicate that while education does influence the observed support of the Court's ban, strong regional difference still exist.

Another characteristic which has a strong influence on virtually every attitude assessed in the survey is if the respondent has lived outside of Arkansas for a year or more. In general, respondents who have remained in Arkansas for their entire lives express far more traditional or conservative positions on issues. The next row of Table 6 contains the expected support for the Court's ruling if each region had the same proportion of respondents who have lived outside of the state. Two regions, White River and Southeast, would be expected to have lower support for this issue because their proportions of residents who have lived outside of Arkansas is higher than is true of the Northwest. In the remaining regions, adjustment for exposure to other states increases the 
approval of the Court's ruling.

The next row contains the expected rates if all regions had the same educational composition and mobility experience as do residents in the Northwest. The Southwest and Central regions would be expected to have decreased support if their composition on these two variables was the same as the Northwest while the remaining five regions would shift toward greater approval. In two regions, the West and Southwest, the impact of standardization is fairly small (1.9 and 4.3 percent of the total difference); however, these two factors account for over 20 percent of the observed differences in the Central and West Central regions.

These same calculations were carried out for the proportion of residents in each of the regions who feel that a woman's place is in the home (see Table 7). As can be seen, all regions with the exception of the Central, would shift toward a more liberal position on this question if their residents had the same level of education as is found in the Northwest. Once again, results are presented for the separate effect of residential experience and the combined effects of education and residence. It should be noted that when the rate is standardized for both factors, all regions shift toward a more liberal position. In three regions, East Arkansas, Central, and West Central, over 50 percent of the observed differences relative to the Northwest are due to compositional effects

In summary, the results presented suggest that although there are sharp regional differences in Arkansas, these differences are confounded by compositional effects. Depending on the nature of the issue considered, compositional effects can alter observed patterns dramatically.

Table 6. Decomposition of Attitudes About Prayer in Public Schools

P L A N N I N G RE G I O N

Favor Ban on

Prayer (\%) ...

NW WR EA SE C WC SW W Total

Observed*

29.924 .6

17.3

12.9

$25.0 \quad 18.4$

8.8

14.120 .8

Number

(149)

(56)

(139)

(131) (305) (98)

$(82)$

(81) (981)

Observed difference

4.0

12.

17.0

4.9

$11.5 \quad 21.1$

15.8

Adjusted for:

Education

$25.9 \quad 19.4$

12.9

23.

Difference

0.0

$\begin{array}{lll}1.7 & -1.6 & -1.0\end{array}$


Blair, Mangold, and Savage

\begin{tabular}{|c|c|c|c|c|c|c|c|}
\hline Native status & 21.7 & 17.8 & 9.1 & 26.1 & 21.5 & 9.8 & 14.2 \\
\hline Difference & 2.9 & -0.5 & 3.8 & -1.1 & -3.1 & -1.0 & -0.1 \\
\hline Education \& Native & 25.1 & 19.3 & 9.2 & 23.6 & 21.3 & 9.7 & 14.4 \\
\hline Difference & -0.5 & -2.0 & 3.7 & 1.4 & -2.9 & -0.9 & -0.3 \\
\hline $\begin{array}{l}\% \text { of total difference } \\
\text { to education \& nativ }\end{array}$ & & 12.5 & 15.9 & 1.8 & 25.2 & 4.3 & 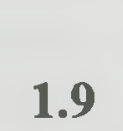 \\
\hline
\end{tabular}

*Values shown are the percent who approve of the Supreme Court's ban on prayer in public schools

Table 7. Decomposition of Attitudes about Women

Women should stay

\begin{tabular}{llllllllll} 
at home (\%) & NW & WR & EA & SE & C & WC & SW & W & Total \\
\cline { 2 - 9 } Observed* & 40.3 & 57.9 & 54.7 & 59.4 & 39.2 & 48.5 & 56.2 & 51.8 & 47.5 \\
& $(149)$ & $(56)$ & $(139)$ & $(131)$ & $(305)$ & $(98)$ & $(82)$ & $(81)$ & $(981)$
\end{tabular}

$\begin{array}{llllllll}\text { Observed difference } & -15.6 & -14.4 & -19.1 & 1.1 & -8.2 & -15.9 & -11.5\end{array}$

Adjusted for:

Education

Difference

$\begin{array}{lllllll}55.9 & 47.7 & 58.8 & 40.6 & 44.7 & 55.8 & 51.8\end{array}$

$\begin{array}{lllllll}2.0 & 7.0 & 0.6 & -1.4 & 3.8 & 0.4 & 0.0\end{array}$

Native status

$\begin{array}{lllllll}58.6 & 54.5 & 57.2 & 36.6 & 48.2 & 56.8 & 50.9\end{array}$

Difference

$\begin{array}{lllllll}-0.7 & 0.2 & 2.2 & 2.6 & 0.3 & -0.6 & 0.9\end{array}$

Education \& Native

$\begin{array}{lllllll}56.5 & 47.0 & 57.6 & 38.4 & 44.1 & 56.0 & 49.3\end{array}$

Difference

$\begin{array}{llllllll}1.4 & 7.7 & 1.8 & 0.8 & 4.4 & 0.2 & 2.5\end{array}$

$\%$ of difference due to education $\&$ native

\section{$\begin{array}{lllllll}9.0 & 53.5 & 9.4 & 72.7 & 53.6 & 1.2 & 21.7\end{array}$}

*Values shown are the percent who feel that a woman should stay at home.

\section{Some Conclusions}

A number of questions were posed early in this essay. What followed were a number of observations on findings relevant to regional differences emerging in a 1986 opinion survey of Arkansans with pertinent references to a somewhat similar survey conducted in 1982 . While some tentative answers can be offered for those questions, the answers 
remain no less tentative than the ones proffered by the Savage and Blair analysis of the 1982 survey.

The 1986 survey does confirm that opinion distributions are not uniformly spread throughout the geographical area of Arkansas, i.e., regional variations in Arkansans' opinions across a wide range of matters of public concern are very apparent. More difficult to gauge is the consistency of those regional opinion patterns over time. While continuing surveys in the state somewhat along the lines of the national General Social Survey would be helpful in more clearly establishing the stable parameters of such regional differences as persist over time, even that would not resolve all the problems. First, much more information is needed just to establish fundamental marker questions. Secondly, a thorough analysis of the role of demographic composition in existing regional differences in opinion distributions is needed so as to be able to differentiate the contributions of both cultural legacy and demographic composition to regional cleavages. Thirdly, any continuing survey of the state would need to be made sensitive to the role of locally-based environmental stimuli producing issue conflicts. While these are often thought of as temporary disturbances, they may also represent transitional phenomena leading to more fundamental changes in cultural heritage or demographic composition.

As to the substantive value of such regional studies, the present authors feel awareness of such regional cleavages will produce a better understanding of how a state population moves to recognize its heritage and its problems. Moreover, this inquiry into regional opinion distributions most clearly shows that Arkansans, however they are spread about the face of the state, tend to agree about important issues confronting them at least as much as they disagree. Nevertheless, the findings here serve as a further caveat to both social scientists and policy practitioners alike: the underlying extent and uniformity of support for any value position should not easily be taken for granted. At the same time, policy practitioners should take note that broad areas of relative consensus for policy action do exist in Arkansas, albeit the directions suggested do not always coincide with the proverbial folk wisdom.

\section{Note}

${ }^{1}$ For further information on the Center's survey activities, contact William D. Mangold, Department of Sociology, University of Arkansas, Fayetteville. With regard to the AHRP, see Darden (1982). 


\section{References}

Darden, W.R. (1982). "Center for Marketing Research and Modeling: From AHRP to

Where?" Arkansas Business and Economic Review 15, 3: 23-15.

Key, V.O., Jr. (1949). Southern Politics in State and Nation New York: Knopf.

Savage, R.L., and D.D. Blair (1984). " Regionalism and Political Opinion in Arkansas: An Exploratory Survey." Arkansas Political Science Journal 5: 59-85.

Savage, R.L., and W.R. Darden (1985). "Recent Trends in Institutional Confidence among Arkansans: Updating Earlier Findings." Arkansas Political Science Journal. 6: 84-92.

Savage, R.L., and R.J. Gallagher (1977). " Politicocultural Regions in a Southern State: An Empirical Typology of Arkansas Counties." Publius, 7, 1: 91-105.

\section{Appendix}

Comparison of Sample with Population. The table below contains the distribution for the sample with estimates for the 1985 Arkansas population. It should be noted that the sample is based on households with a working telephone while the census values are for all households. Because the sample was obtained in 1986 it is simply not feasible to compare many of the detailed sample characteristics with known population values because population characteristics are only available from the decennial census

\begin{tabular}{|c|c|c|}
\hline \multicolumn{3}{|c|}{$\begin{array}{l}\text { Comparison of the Sample with } \mathrm{F} \\
1985 \text { Census values }\end{array}$} \\
\hline Age & Census & Sample \\
\hline $18-44$ & 53.3 & 54.8 \\
\hline $45-64$ & 27.3 & 25.5 \\
\hline 65 \& over & 19.3 & 19.7 \\
\hline Total & $100.0 \%$ & $100.0 \%$ \\
\hline \multicolumn{3}{|l|}{ Race } \\
\hline White & 83.0 & 85.1 \\
\hline Nonwhite & 17.0 & 15.9 \\
\hline Total & $100.0 \%$ & $100.0 \%$ \\
\hline
\end{tabular}

